triển 6 tháng (CI 95\%:5,5-6,5).

- Tiền sử trước đó chưa từng điều trị hóa chất liên quan đên tăng thời gian sống thêm bệnh không tiến triển (10 tháng so với 6 tháng, $\mathrm{p}=0,041)$.

\section{TÀl LIẸU THAM KHẢO}

1. Nguyễn Bá Đức (2007), Chẩn đoán và điều trị ung thư, NXB Y họ

2. Bùi Diệu, (2011), Một số bệnh ung thư phụ nữ, NXB Y hoc.

3. Đặng Tiến Giang và cộng sự (2020). Bước đầu đánh giá kết quả phác đồ lyposomal doxorubicin trên bệnh nhân ung thư nội mạc tử cung tái phát tại bệnh viện K. Tap chí y học Việt Nam, 497, 45-48.

4. Pectasides $D$, Xiros $N$, Papaxoinis $G$, et al. Carboplatin and paclitaxel in advanced or metastatic endometrial cancer. Gynecol Oncol.
2008;109(2):250-254. doi:10.1016/ j.ygyno.2008.01.028

5. Cohen CJ. Cytotoxic chemotherapy for patients with endometrial carcinoma. Clin Obstet Gynaecol. 1986;13(4):811-824

6. Miller DS, Filiaci VL, Mannel RS, et al. Carboplatin and Paclitaxel for Advanced Endometrial Cancer: Final Overall Survival and Adverse Event Analysis of a Phase III Trial (NRG Oncology/GOG0209). J Clin Oncol. 2020; 38(33):3841-3850. doi:10.1200/JCO.20.01076.

7. Trope CG, Alektiar KM, Sabbatini P, Zaino RJ. Corpus: epithelial tumors. In: Hoskins WJ, Perez CA, Young RC, Barakat RR, Markman M, Randall $M E$, eds. Principles and Practice of Gynecologic Oncology. $4^{\text {th }}$ ed. Philadelphia: Lippincott Williams and Wilkins;2005:823-872.

8. Huijgens ANJ, Mertens HJMM. Factors predicting recurrent endometrial cancer. Facts Views Vis Obgyn. 2013;5(3):179-186.

\title{
MỐI TƯONG QUAN GIỮA NỒNG Độ HS-CRP VỚI MộT SỐ CHỈ SỐ XÉT NGHIỆM HÓA SINH LIÊN QUAN TRÊN BỆNH NHÂN ĐÁI THÁO ĐƯờNG TYP 2
}

\section{TÓM TẮT}

Mở đâu: Tình trạng viêm kéo dài gây nên các biến chứng mach máu trong bênh đái tháo đường. Nếu không được kiểm soát và điều trị kịp thời bệnh nhân có thể tàn phế, tử vong. Xét nghiệm hs-CRP máu như một chỉ dấu sinh học hữu ích của tình trạng viêm mạch mạn tính, nhằm hố trợ chẩn đoán, theo dõi điều trị và phát hiện biến chứng một cách hiệu quả cho bệnh nhân đái tháo đường typ 2. Mục tiêu: Khảo sát mối liên quan giữa nồng độ hs-CRP máu với các chỉ số xét nghiệm hóa sinh (glucose máu đói, HbA1c, lipid máu) trển bệnh nhân đái tháo đường typ 2. Đối tượng: 238 người chia 2 nhóm: Nhóm bệnh gồm 118 bênh nhân đái tháo đường typ 2 và nhóm chứng gồm 120 người bình thường khỏe mạn, có độ tuổi và giới tính tương đương với nhóm bệnh. Phương pháp nghiên cứu: Nghiên cứu mô tả cắt ngang có đối chứng. Bệnh nhân được khám lâm sàng, khai thác tiền sử, bệnh sử, lấy máu tĩnh mạch lúc đói định lượng nồng độ hs-CRP, glucose, $\mathrm{HbA} 1 \mathrm{c}$, cholesterol toàn phần, LDL-C, HDL-C và triglyceride. Chẩn đoán đái tháo đường typ 2 theo tiêu chuẩn của ADA 2020. Kết quả: Nồng độ trung bình hs-CRP máu $(\mathrm{mg} / \mathrm{L})$ của nhóm bệnh và nhóm chứng lần lượt là $3,9 \pm 1,7$ so với $1,7 \pm 1,1 \mathrm{mg} / \mathrm{L}(\mathrm{p}<0.001)$. Sự khác biệt này có ý nghĩa thống kê. Bệnh nhân có nồng độ hs-CRP ở các mức độ nguy cơ cao và nguy cơ trung bình đối với

*Đai hoc Y Dước TP. Hồ Chí Minh

Chịu trách nhiệm chính: Lâm Vĩnh Niên

Email: nien@ump.edu.vn

Ngày nhận bài: 23.8.2021

Ngày phản biên khoa họ: 18.10.2021

Ngày duyệt bài: 28.10.2021

\section{Nguyễn Lê Hà Anh*, Nguyễn Thanh Trầm*, Vũ Trí Thanh*, Lâm Vĩnh Niên*}

bệnh tiểu đường typ 2 rất phổ biến (99,2\%). Trong đó, tỷ lệ phần trăm bệnh nhân ở các mức cao, trung bình và thấp lần lượt là 72,$9 ; 26,3$ và 0,8 . Nồng độ hsCRP máu tương quan thuận với glucose, HbA1c, cholesterol toàn phân, $L D L-C$ và triglyceride, tương quan nghịch với HDL-C. Kết luận: Nồng độ trung bình hs-CRP máu của người mắc đái tháo đường typ 2 cao hơn người không mắc đái tháo đường typ 2. Có mối tương quan thuận và có ý nghĩa thống kê giữa hsCRP với glucose, $\mathrm{HbA} 1 \mathrm{c}$, cholesterol toàn phần, $\mathrm{LDL}-\mathrm{C}$ và triglyceride, tương quan nghịch với $\mathrm{HDL}-\mathrm{C}$.

Từ khóa: hs-CRP, đái tháo đường typ 2.

\section{SUMMARY}

\section{CORRELATION BETWEEN HIGH-SENSITIVITY C- REACTIVE PROTEINS LEVELS (hS-CRP) AND SOME BIOCHEMICAL TEST INDEX IN TYPE 2} DIABETES PATIENTS

Background: Prolonged in inflammation causes vascularcomplications in diabetes. If not controlled and treated promptly, the patient can become disabled and die. Blood hs-CRP test as a useful biomarker of chronic vasculitis, in order to support diagnosis, monitor treatment and detect complications effectively for patients with type 2 diabetes. Aim: To examine the correlation between blood hs-CRP levels and some biochemical test index (glucose, HbA1c, total cholesterol, LDL-C, HDL-C and triglyceride) in type 2 diabetes patient. Sample: 238 pepple divided into two groups: group of 118 patients with type 2 diabetes and group of 220 healthy people (control group) having age and gender equivalent to the patient group. Method: A cross-sectional descriptive study. Patients under clinical examination, history abstraction, intravenous blood werw measured levels 
of hs-CRP, glucose,HbA1c, total cholesterol, LDL-C, HDL-C and triglyceride. Diagnose type 2 diabetes according to ADA 2020. Results: Blood hs-CRP $(\mathrm{mg} / \mathrm{L})$ in the patient and control groups were 3,9 \pm 1,7 compared to $1,7 \pm 1,1 \mathrm{mg} / \mathrm{L} \quad(p<0,001)$. This difference is statistically significant. Patients with high levels of hs-CRP at high and average rick for heart disease were $99.2 \%$. In which, the percentage of patients at high, medium and low levels were72.9; 26.3 and 0.8 respectively. Blood hs-CRP levels were positive correlated with glucose, HbA1c,total cholesterol, LDL-C and triglyceride, inverse correlated with triglyceride. Conclusion: The blood hs-CRP levels in type 2 diabetes patients were higher than control group. There is a positive correlation between hs-CRP levels in blood with glucose, HbA1c, total cholesterol, LDL-C and triglyceride, nagative correlated with triglyceride.

Keywords; hs-CRP, type 2 diabetes.

\section{I. ĐẶT VẤN ĐỀ}

Đái tháo đường (ĐTÐ) typ 2 chiếm khoảng $90 \%$ trong tất cả các trường hợp ĐTĐ là bệnh rối loạn chuyển hóa mạn tính phổ biến trên thế giới cũng như ở Việt Nam. Tỷ lệ mắc ĐTĐ ngày càng tăng nhanh trong dân số. Theo ước tính của Liên đoàn Đái Tháo Đường thế giới (IDF) năm 2017 trên thế giới chỉ có khoảng 424,9 triệu người mắc bệnh ĐTÐ (ở độ tuổi từ 20-79) thì tới năm 2045 con số này sẽ là 629 triệu người (tăng $48 \%$ ). ĐTÐ được xếp vào nhóm 10 bệnh mãn tính không lây nhiễm đứng hàng đầu của thế kỷ 21.

Các biến chứng mạn tính thường gặp nhất ở bệnh nhân ĐTÐ là biến chứng tim mạch, mắt, thận và thần kinh, đặc biệt là các biến chứng vế mạch máu ảnh hưởng rất nhiều đến chất lượng cuộc sống, tăng tỷ lệ tàn tật và tử vong cho người bệnh. Các biến chứng này thậm chí có ngay tại thời điểm bệnh mới được phát hiện và là nguyên nhân chính gây tử vong ở bệnh nhân ĐTĐ(2).

Có nhiều nghiên cứu cho thây có mối liên quan giữa bệnh $Đ T Ð$ với tình trạng viêm kéo dài gây nên các biến chứng mạch máu. Phản ứng viêm tại lớp nội mạc mạch máu không những tham gia vào cở chể bệnh sinh của ĐTĐ mà còn là yếu tố làm duy trì, phát triển quá trình biến chứng và làm tăng tỷ lệ tử vong ở bệnh nhân ĐTÐ(6). Quá trình viêm này có thể được phát hiện bằng xét nghiệm hs-CRP - một xét nghiệm có nhiều ưu điểm so với các marker viêm khác bởi sự ổn định, phổ biến và đã được chuẩn hóa quốc tế.

Vì vậy, chúng tôi tiến hành thực hiện đề tài này nhẳm mục đích khảo sát mối tướng quan giữa nồng độ hs-CRP với một số chỉ số xét nghiệm hóa sinh liên quan trên bệnh nhân đái tháo đường typ 2.
II. ĐỐl TƯỢNG VÀ PHƯƠNG PHÁP NGHIÊN CỨU

1. Đối tượng nghiên cứu: Gồm 238 người chia 2 nhóm: Nhóm bệnh gồm 118 bệnh nhân đái tháo đường typ 2 được lựa chọn theo tiêu chuẩn chẩn đoán của Hiệp hội Đái tháo đường Hoa Kỳ (ADA) năm 2020 và tiêu chuẩn loại trừ được khám, chẩn đoán, điều trị tại phòng khám Nội tiết, Bệnh viện Đại học Y dược thành phố Hồ Chí Minh cơ sở 2. Nhóm chứng gồm 120 người bình thường khỏe manh, không mắc đái tháo đường typ 2 có độ tuổi và giới tính tương đương với nhóm bệnh.

2. Phướng pháp nghiên cứu: Nghiên cứu mô tả cắt ngang có đối chứng.

Phương pháp thu thập số liệu: Sử dụng phương pháp chọn mẫu liên tục.

Bệnh nhân được khám lâm sàng, khai thác tiền sử, bệnh sử thỏa tiêu chuẩn chọn mẫu sẽ được đưa vào nghiên cứu. Ghi nhận thông tin nền từ hồ sơ bệnh án, đo huyết áp và đo nhân trắc. Thực hiện các xét nghiệm hóa sinh gồm: Máu tĩnh mạch được lấy vào buổi sáng sau khi nhịn qua đềm (10-12 giờ) chống đông bằng lithium heparin và EDTA.

Tại phòng xét nghiệm, bệnh nhân được lấy $4 \mathrm{ml}$ máu tĩnh mạch, xét nghiệm HbA1c dùng chất chống đông EDTA, tube chống đông lithium heparin ly tâm 3000 vòng/ phút trong 5 phút, tách lấy huyết tương để định lượng: định lượng hs-CRP, glucose, cholesterol toàn phần, LDL-C, $H D L-C$ và triglyceride $(T G)$, thực hiện xét nghiệm trong vòng 30 phút sau khi lây máu.

Định lượng nồng độ hs-CRP: hs-CRP được định lượng theo phương pháp miễn dịch độ đục với hóa chất của hãng Olympus cung cấp, thực hiện trên hệ thống máy $A U 680$ của hãng Beckman Coulter do Nhật Bản sản xuất.

Phân tích số liệu: số liệu được thu thập qua phiếu nghiên cứu, xử lý số liệu bằng phân mềm Epidata 3.1 và Stata.

\section{KẾT QUẢ NGHIÊN CỨU}

\section{1 Đặc điểm của đối tượng nghiên cứu Tuổi và giới}

Bảng 1. Đặc điểm về tuổi và giới

\begin{tabular}{|c|c|c|c|}
\hline $\begin{array}{l}\text { Đặc } \\
\text { điểm }\end{array}$ & $\begin{array}{c}\text { Nhóm bệnh } \\
(\mathrm{n}=118)\end{array}$ & $\begin{array}{l}\text { Nhóm } \\
\text { chứng } \\
(\mathrm{n}=120)\end{array}$ & $\mathbf{p}$ \\
\hline & $\begin{array}{c}\text { Tân số (Tỉ } \\
\text { lệ \%) }\end{array}$ & $\begin{array}{c}\text { Tân số (Tí } \\
\text { lệ \%) }\end{array}$ & \\
\hline Tuổi ${ }^{1}$ & $\begin{array}{c}56,6 \pm 11,4 \\
(23 / 84)\end{array}$ & $\begin{array}{c}54,5 \pm 8,6 \\
(30 / 72)\end{array}$ & 0,113 \\
\hline \multicolumn{4}{|c|}{ Giới tính } \\
\hline Nữ & $72(61,0)$ & $81(67,5)$ & 0,297 \\
\hline Nam & $46(39,0)$ & $39(32,5)$ & \\
\hline
\end{tabular}


${ }^{1}$ Trung bình \pm Độ lệch chuẩn (GTLN/GTNN)

Tuổi bệnh nhân trong khoảng từ 23 đến 84 , trong đó tuổi trung bình của nhóm bênh và nhóm chứng tương đương nhau. Không có sự khác biệt có ý nghĩa thống kê về giới tính giữa nhóm bệnh và nhóm chứng $(p>0,05)$.

3.2 Đặc điểm nhân trắc học

Bảng 2. Một số đặc điểm lâm sàng của nhóm bệnh nhân ĐTÐ typ 2

\begin{tabular}{|c|c|c|}
\hline Đặc điếm & Tân số & Tỉ lệ (\%) \\
\hline \multicolumn{3}{|c|}{ hóm BMI $\left(\mathrm{kg} / \mathrm{m}^{2}\right)$} \\
\hline$<23$ & 44 & 62,7 \\
\hline$\geq 23$ & 74 & 37,3 \\
\hline Tăng huyết áp & 76 & 64,4 \\
\hline
\end{tabular}

Có 62,7\% đối tượng nghiên cứu ở nhóm bênh nằm trong nhóm thừa cân, béo phì (BMI $\geq 23$ ).

Tỷ lệ mắc tăng huyết áp ở nhóm bệnh nhân ĐTĐ typ 2 là 64,4\%.

2.1. Kêt quả định lượng hs-CRP

Bảng 10. So sánh nồng độ hs-CRP giữa hai nhóm nghiên cứu

\begin{tabular}{|c|c|c|c|}
\hline Đặc điểm & $\begin{array}{c}\text { Nhóm } \\
\text { bệnh } \\
(n=118)\end{array}$ & $\begin{array}{c}\text { Nhóm } \\
\text { chứng } \\
(n=120)\end{array}$ & $\mathbf{P}$ \\
\hline $\begin{array}{c}\text { hs - CRP } \\
\text { (mg/L) }\end{array}$ & $3,9 \pm 1,7$ & $1,7 \pm 1,1$ & $<\mathbf{0 , 0 0 1}$ \\
\hline
\end{tabular}

Nồng độ hs - CRP trung bình ở nhóm mắc ĐTĐ typ 2 cao hơn so với nhóm người bình thường, sự khác biệt có ý nghĩa thống kê $(p<0,001)$.

3. Mối tương quan giữa nồng độ hs-CRP với một số yếu tố liên quan trên bệnh nhân ĐTÐ typ 2

3.1. Tương quan giữa hs-CRP với tuổi và giới

Bảng 11. Mối tương quan giữa nồng độ $h s-$ CRP với tuối

\begin{tabular}{|c|c|c|c|}
\hline $\begin{array}{c}\text { hs-CR(mg/I } \\
\text { Đặc điểm }\end{array}$ & $\begin{array}{c}\text { Phương trình } \\
\text { hồi quy }\end{array}$ & $\mathbf{r}$ & $\mathbf{p}$ \\
\hline Tuổi & $\begin{array}{c}\text { hs-CRP }=3,38+ \\
0,01 \times \text { Tuối }\end{array}$ & 0,07 & 0,48 \\
\hline
\end{tabular}

Nồng độ hs-CRP có sự tương quan lỏng lẻo và không có ý nghĩa thống kê với tuổi $(r=0,07$, $\mathrm{p}>0,05)$.

Bảng 12. Mối tương quan giữa nồng độ hs$C R P$ với giới tính

\begin{tabular}{|c|c|c|c|}
\hline $\begin{array}{c}\text { hs-CRP (mg/I) } \\
\text { bạac điểm }\end{array}$ & $\begin{array}{c}\text { Tân } \\
\text { số }\end{array}$ & $\begin{array}{c}\text { Trung bình } \mathbf{3} \\
\text { Độ lệch chuẩn }\end{array}$ & $\mathbf{p}$ \\
\hline Giới tính & & & \\
\hline Nữ & 72 & $3,9 \pm 0,2$ & 0,874 \\
\hline Nam & 46 & $4,0 \pm 0,3$ & \\
\hline
\end{tabular}

Không có mối tương quan giữa nồng độ hs CRP với giới tính trong nhóm bệnh ( $p>0,05)$.

3.2. Mối tương quan giữa nồng độ hsCRP với một số đặc điểm lâm sàng

Bảng 13. Mối tương quan giữa nồng độ $h s-$
$C R P$ với $B M I$ và tăng huyêt áp

\begin{tabular}{|c|c|c|c|}
\hline $\begin{array}{l}\text { hs-CRP } \\
\text { (mg/I) } \\
\text { Đặc điểm }\end{array}$ & Tân số & $\begin{array}{c}\text { Trung bình } \pm \\
\text { Đố lệ̂ch } \\
\text { chuẩn }\end{array}$ & p \\
\hline \multicolumn{4}{|c|}{ BMI $\left(\mathbf{k g} / \mathbf{m}^{2}\right)$} \\
\hline$<23$ & 44 & $3,4 \pm 1,7$ & 0,009 \\
\hline$\geq 23$ & 74 & $4,2 \pm 1,7$ & \\
\hline \multicolumn{4}{|c|}{ Tăng huyết áp } \\
\hline Có & 76 & $4,7 \pm 0,3$ & $<0,001$ \\
\hline Không & 42 & $3,5 \pm 0,2$ & \\
\hline
\end{tabular}

Nồng độ hs-CRP trung bình của bệnh nhân ở nhóm thừa cân và béo phì cao hơn so với bênh nhân nhóm bình thường và gầy, sự khác biệt có ý nghĩa thống kê $(p<0,05)$.

Bệnh nhân tăng huyết áp có nồng độ hs-CRP trung bình cao hớn có ý nghĩa thống kê so với bệnh nhân không tăng huyết áp $(p<0,001)$.

3.3. Tương quan giữa hs-CRP với Glucose máu đói và HbA1c

Bảng 14. Mối tương quan giữa nồng độ hs$C R P$ với Glucose máu đói và $H b A 1 c$

\begin{tabular}{|c|c|c|c|}
\hline $\begin{array}{r}\text { hs-CRP } \\
(\mathrm{mg} / \mathrm{I}) \\
\text { Đăc điểm }\end{array}$ & $\begin{array}{l}\text { Phương trình } \\
\text { hối quy }\end{array}$ & $\mathbf{r}$ & $\mathbf{p}$ \\
\hline $\begin{array}{c}\text { Glucose máu } \\
\text { đói }\end{array}$ & $\begin{array}{c}\text { hs-CRP }=2,29+ \\
0,01 \times \text { Glucose }\end{array}$ & 0,45 & $<0,001$ \\
\hline HbA1c & $\begin{array}{c}\text { hs-CRP }=1,11+ \\
0,34 \times \text { HbA1c }\end{array}$ & 0,46 & $<0,001$ \\
\hline
\end{tabular}

Có mối tương quan thuận, mức độ khá giữa nồng độ hs-CRP với glucose máu đói $(r=0,45$, $p<0,001)$ và $\operatorname{HbA} 1 \mathrm{c}(r=0,45, p<0,001)$. Nếu nồng độ hs-CRP tăng lên 1 đơn vị thì Glucose máu đói và $\mathrm{HbA1c}$ tăng lần lượt $0,01 \mathrm{mg} / \mathrm{dL}$ $(p<0,001)$ và $0,34 \mathrm{mg} / \mathrm{dL}(\mathrm{p}<0,001)$.

3.4. Tương quan giữa hs-CRP với nguy cơ về lipid máu

Bảng 15. So sánh nồng độ hs-CRP giữa nhóm có tăng nguy cơ về lipid máu với nhóm không tăng

\begin{tabular}{|c|c|c|c|}
\hline $\begin{array}{l}\text { hs-CRP }(\mathrm{mg} / \mathrm{l}) \\
\text { Đặc điểm }\end{array}$ & $\begin{array}{l}\text { Tân } \\
\text { số }\end{array}$ & $\begin{array}{c}\text { Trung bình } \\
\pm \text { Độ lệ̂̉ch } \\
\text { chuấn }\end{array}$ & p \\
\hline \multicolumn{4}{|c|}{ Phân nhóm Cholesterol toàn phần (mg/dL) } \\
\hline Không tăng (<200) & 65 & $3,8 \pm 0,2$ & 0,280 \\
\hline Có tăng $(\geq 200)$ & 53 & $4,2 \pm 0,3$ & \\
\hline \multicolumn{4}{|c|}{ Phân nhóm LDL (mg/dL) } \\
\hline Không tăng $(<130)$ & 77 & $3,7 \pm 0,2$ & 0,118 \\
\hline Có tăng $(\geq 130)$ & 41 & $4,3 \pm 0,3$ & \\
\hline \multicolumn{4}{|c|}{ Phân nhóm HDL (mg/dL) } \\
\hline Không giảm (>40) & 76 & $3,7 \pm 0,2$ & 0,086 \\
\hline Có giảm $(\leq 40)$ & 42 & $4,4 \pm 0,3$ & \\
\hline \multicolumn{4}{|c|}{ Phân nhóm Triglycerid (mg/dL) } \\
\hline Không tăng ( $\leq 150)$ & 53 & $3,7 \pm 0,2$ & 0,120 \\
\hline Có tăng $(>150)$ & 65 & $4,2 \pm 0,2$ & 0,280 \\
\hline
\end{tabular}




\section{BÀN LUÂNN}

Đặc điểm đối tượng nghiên cứu. Đối tượng nghiên cứu của chúng tôi bao gồm 118 bệnh nhân ĐTÐ typ 2 và 120 người bình thường với sự tương đồng về nhóm tuổi và giới tính. Sự lựa chọn đối tượng tương đồng giữa hai nhóm giúp đảm bảo tính khách quan trong nghiên cứu so sánh đối chứng.

Tỷ lệ phân bố theo tuổi ở nhóm bệnh nhân ĐTÐ typ 2 trong nghiên cứu của chúng tôi có sự tương đồng với nghiên cứu được thực hiện năm 2019 trên bệnh nhân điều trị ngoại trú tại Bắc Giang (tuổi trung bình là $58,88 \pm 11,47$ ) và nhóm bệnh có tuổi từ 50-69 chiếm tỷ lệ cao nhất $(71,5 \%)^{(1)}$. Kết quả nghiên cứu cho thấy phần lớn bệnh nhân là nữ giới (61\%).

Các nghiên cứu trên thế giới cũng cho thấy tỷ lệ mắc ĐTĐ typ 2 tăng theo tuổi và thường gặp ở phụ nữ. Nếu lứa tuổi 30-40 tuổi có tỷ lệ mắc ĐTĐ typ 2 là 40\% thì ở lứa tuổi 40-50 tuổi tỷ lệ này là $60 \%{ }^{(7)}$. Nghiên cứu tai Ai Câp (2018) nhận thấy ĐTĐ typ 2 gặp nhiều nhất ở phụ nũ $(82,9 \%)$ với tuổi trung bình là $50.83 \pm 8.26$ tuối ${ }^{(4)}$. Điều này hoàn toàn phù hợp với y văn thế giới bởi lẽ tuổi càng cao thì càng có nguy cơ mắc bệnh ĐTÐ, đặc biệt là phụ nữ ở sau tuổi mãn kinh, do tuổi cao và do thay đổi nội tiết tố nên sẽ gia tăng nguy cơ mắc bệnh ĐTÐ.

Tỷ lệ bệnh nhân ĐTĐ typ 2 tăng huyết áp cao hơn so với không tăng huyết áp. Điều này là do ĐTÐ và tăng huyết áp có mối quan hệ thuận nghịch. Huyết áp cao khiến đường huyết tăng gây nên ĐTĐ và làm biến chứng xảy ra nhanh hơn. Ngược lại, sự xuất hiện của ĐTĐ làm gia tăng đáng kể tình trang tăng huyêt áp.

Phần lớn bệnh nhân ĐTĐ typ 2 bị thừa cân, béo phì $(64,4 \%)$. Điều này cho thấy, những người có chî số BMI càng cao thì càng có nguy cơ mắc ĐTÐ typ 2.

Mối tương quan giữa nông độ hs-CRP với một số yếu tố liên quan trên bệnh nhân ĐTÐ typ 2. Kết quả nghiên cứu cho thấy nồng độ hs-CRP ở nhóm mắc ĐTÐ typ 2 cao hơn nhóm bình thường. Bệnh nhân có nồng độ hsCRP thuộc nhóm nguy cơ cao chiếm tỷ lệ chủ yếu $(72,9 \%)$, tiếp đến là nhóm nguy cơ trung bình $(26,3 \%)$ và nhóm ít nguy cơ chiếm tỷ lệ thấp nhất.

Nhận thấy rằng bệnh nhân ĐTĐ typ 2 bị thừa cân, béo phì và tăng huyết áp có nồng độ hsCRP cao hơn người bình thường $(p<0,05)$. ĐTÐ, tăng huyết áp và tăng $L D L, \ldots$ là các yếu tố nguy cơ gây tổn thương nội mạc mạch máu. Sự tổn thương này khởi động quá trình viêm mạch máu và hậu quả là gây rối loạn chức năng các cơ quan.

Trong nghiên cứu của chúng tôi, nồng độ glucose máu đói và HbA1c ở nhóm ĐTÐ typ 2 cao hơn so với nhóm chứng. Khi phân tích mối liên quan ở nhóm bệnh, tìm thây có mối tương quan thuận, mức độ khá giữa nồng độ hs-CRP với glucose máu đói và HbA1c $(p<0,001)$. hs-CRP là một chỉ điểm viêm có độ nhạy cao gấp hàng trăm lần so với CRP, nó rất nhạy với các tổn thương mạch máu, đặc biệt là ở vi mạch và thường được dùng để đánh giá nguy cơ tim mạch. Nhiêu tác giả trên thế giới đã đưa ra kết luận có mối tương quan giữa nồng độ hs-CRP với việc kiểm soát đường huyết (HbA1c). Điều này đồng nghĩa với việc bệnh nhân ĐTÐ kiểm soát đường huyết càng kém thì nguy cơ tim mạch càng tăng.

Nghiên cứu cho thấy không có sự khác biệt về nồng độ trung bình của hs-CRP ở nhóm có và không có rối loạn lipid máu. Kết quả này tương đồng với nghiên cứu được thực hiện tại Sudan (2019) nhận xét không có sự liên quan giữa nồng độ hs-CRP với các chỉ số lipid máu(3). Tuy nhiên, một số nghiên cứu khác lại tìm thấy mối tương quan giữa nồng độ hs-CRP với một số chỉ số lipid máu. Cụ thể, một nghiên cứu tiền cứu tại Ấn Độ (2019) đã tìm thãy mối tương quan giữa nồng độ hs-CRP với $\mathrm{HDL}(r=-0,286, p<0,05)$ và với TG $(r=0,310, p<0,05)^{(8)}$. Hay một nghiên cứu khác thực hiện trên 2520 người, trong đó có 1410 bệnh nhân ĐTĐ typ 2 cũng cho thây có mối tương quan giữa nồng độ hs-CRP với TG $(r=0,08, p=0,02)$. Điều này có thể là do sự khác biệt về các thiết kế nghiên cứu, cõ̃ mẫu và các đặc tính của mẫu giữa nghiên cứu của chúng tôi với các nghiên cứu trên.

\section{KẾT LUẦN}

Nồng độ hs-CRP trung bình $(\mathrm{mg} / \mathrm{l})$ của người mắc ĐTÐ typ 2 cao hơn so với người bình thường $(3,9 \pm 1,7$ so với $1,7 \pm 1,1 ; \mathrm{p}<0,001)$. Có mối tương quan thuận, mức độ khá giữa nồng độ hs-CRP với glucose máu đói $(r=0,45$, $p<0,001)$ và HbA1c $(r=0,45, p<0,001)$. Bệnh nhân ĐTÐ typ 2 bị thừa cân, béo phì và tắng huyết áp có nồng độ hs-CRP cao hơn có ý nghĩa thống kê so với người bình thường $(p<0,05)$. Nồng độ glucose máu đói và HbA1c ở nhóm ĐTÐ typ 2 cao hơn so với nhóm chứng, sự khác biệt có ý nghĩa thống kê $(p<0,001)$. Không có sự liền quan có ý nghĩa thống kê giữa nồng độ hs-CRP với tuổi, giới tính và rối loạn lipid máu $(p>0,05)$.

\section{TÀI LIỆU THAM KHẢO}

1. Nhẩn Nguyễn Trọng, Thành Vũ Văn Thực trạng kiến thức và thực hành về chế độ ăn uống của 
người bệnh đái tháo đường type 2 điều trị ngoại trú tại Bềnh viện Nội tiết tỉnh Băc Giang năm 2019 Khoa hoc Điều dưỡng, 2019, tr. 97-104.

2. Vinh Phạm Nguyênn, Đái Tháo Đường và bệnh Mach Và̀nh: tâm quan trọng của kiểm soát tích cực LDL-C, Hội nghị khoa học toàn quốc lần VI của hội Nồi tiết và Đái tháo đường Viêt Nam, 2012, tr. 152.

3. Aljack HA, High Sensitive C Reactive Protein in Sudanese Type 2 Diabetic Patients, Sudan Journal of Medical Sciences, 2019, pp. 132-142.

4. Elimam $\mathbf{H}$ et al., Inflammatory markers and control of type 2 diabetes mellitus, Diabetes \& Metabolic Syndrome: Clinical Research \& Reviews, 2018, pp. 800-804.

5. Kashinakunti SV, Serum High Sensitive - C Reactive Protein Levels in Type 2 Diabetes Mellitus
-A Case Control Study, International Journal of Biochemistry Research \& Review, 2016, pp. 1-8.

6. Roopakala MS, Evaluation of high sensitivity creactive protein and glycated hemoglobin levels in diabetic nephropathy, Saudi Journal of kidney diseases and transplantation, 2012, pp. 286.

7. Singh $\mathbf{M}$, High-sensitivity $\mathbf{C}$-reactive protein, Malondialdehyde and their association with Glycated hemoglobin (HbA1c) in type 2 diabetes patients, International Journal of Health and Clinical Research, 2020, pp. 81-86.

8. Singh $\mathbf{N}$, A cross-sectional study on association of high-sensitivity C-reactive proteins (HS-CRP) with dyslipidemia in type 2 diabetic patients of Haryana region, International J. of Healthcare and Biomedical Research, 2019, pp. 30-39.

\section{ĐặC ĐIỂM LÂM SÀNG CỦA HộI CHỨNG SẢNG CẤP DẠNG KÍCH ĐộNG Ở BÊ̂NH NHÂN NGộ ĐộC CẤP}

\section{TÓM TẮT}

Mục tiêu: Mô tả đăc điểm lâm sàng của hôii chứng sảng cấp dạng kích động ở bệnh nhân ngộ độc cấp tại Trung tâm chống độc Bệnh viện Bạch Mai. Phương pháp: Nghiên cứu mô tả tiến cứu trên 48 bệnh nhân có hội chứng sảng cấp dạng kích động do ngộ độc cấp tại trung tâm chống độc,Bệnh viện Bạch Mai từ tháng 1 năm 2020 tới tháng 10 năm 2021. Kết quả: Trong số bệnh nhân nghiên cứu, nam chiếm 72,9\%, gặp nhiều nhất ở nhóm tuổi 18-19 (64,6\%), đa số là lao động tự do $(71,7 \%)$. Tỷ lệ triệu chứng lâm sàng kích động với mức độ nặng là $100 \%$. Các triệu chứng thường gặp là không sợ đau $(50 \%)$, thở nhanh $(97,7 \%)$, vã mồ hôi $(70,8 \%)$, không làm theo lệnh $(83,3 \%)$, tăng cường cơ $(81,3 \%)$, mêtt mỏi $(77,1 \%)$, tăng thân nhiệt $(85,4 \%)$, quần áo không phù hợp $(54,6 \%)$, co giât $(31,3 \%)$, tăng phản xa gân xương $(72,9 \%)$, giãn đồng tử $(56,3 \%)$ và run $(47,9 \%)$, tăng trương lực cơ $(79,2 \%)$, huyết áp tâm thu trung bình $135,0 \pm 10,6 \mathrm{mmHg}$, nhịp tim trung bình là 120,4 \pm 13,9. Kết luận: Hội chứng sảng cấp dang kích động ở bệnh nhân ngộ độc cấp là một cấp cứu lâm sàng với biểu hiên mức độ kích động nặng, nhiều triệu chứng thực tổn nặng như tăng thân nhiệt, tăng trương lực cớ, co giât... cân được xác đinh và xứ trí nhanh chóng.

Tư khóa: Hội chứng sảng cấp dạng kích động, ngộ độc cấp

\footnotetext{
${ }^{1}$ Trường Đại học Y Hà Nội,

2Trung tâm Chống độc,

${ }^{3}$ Viện sức khỏe tâm thần quốc gia,

${ }^{4}$ Bềnh viện đa khoa tỉnh Vînh Phúc

Chịu trách nhiệm chính: Đỗ Đình Lượng

Email: dodinhluong28108@gmail.com

Ngày nhận bài: 23.8.2021

Ngày phản biên khoa hoc: 25.10.2021

Ngày duyệt bài: 2.11.2021
}

Đỗ Đình Lượng ${ }^{1,4}$, Đặng Thị Xuân², Nguyễn Văn Tuấn ${ }^{1,3}$, Hà Trần Hưng ${ }^{1,2}$

\section{SUMMARY \\ CLINICAL FEATURES OF EXCITED DELIRIUM SYNDROME IN ACUTE POISONINGS}

Objectives: to describe the clinical characteristics of acute delirium agitation in acute poisoned patients at Vietnam Poison Control Center, Bach Mai Hospital. Methods: A prospective observational study included 48 patients with acute delirium due to acute poisoning at the Poison Control Center from January 2020 to October 2021. Results: most of the study patients were male $(72.9 \%)$, in the age group of $18-19$ years old $(64.6 \%)$, and unemployed $(71.7 . \%)$. The rate of severe agitation was $100 \%$. The common symptoms were: not afraid of pain $(50 \%)$, rapid breathing $(97.7 \%)$, sweating $(70.8 \%)$, not following orders $(83.3 \%)$, increase in muscle strength $(81.3 \%)$, loss of fatigue $(77.1 \%)$, increase in body temperature $(85.4 \%)$, inappropriate clothing (54.6), delusions of harm $(54.3 \%)$, delusions of jealousy $(2.2 \%)$, panic attacks of pride $(2.3 \%)$, no delusions $(41.3 \%)$, patients have hallucinations $43.8 \%$, hallucinations visual acuity $25.0 \%$ without hallucinogenic disorder $31.2 \%$, mean systolic blood pressure was $135.0 \pm 10.6$, mean heart rate was $120.4 \pm 13.9$. Conclusion: Agitated delirium syndrome in acute poisoned patients was a clinical emergency with severe agitation, many serious signs such as hyperthermia, increased muscle tone, convulsions, etc. required prompt identified and treated.

Keywords; Excited delirium syndrome, acute poisoning

\section{I. ĐĂT VẤN ĐỀ}

Hội chứng sảng cấp dạng kích động (Excited Delirium syndrome ExDS) theo Hiệp hội bác sĩ cấp cứu Hoa Kỳ (ACEP-American of college emergency physician) được định nghĩa là một tình trạng sảng cấp kết hợp với hoạt động dữ dội 